\title{
AAV2-mediated interleukin-12 in the treatment of malignant brain tumors through activation of NK cells
}

\author{
TSUNG-LANG CHIU ${ }^{1,2}$, SHINN-ZONG LIN ${ }^{3}$, WAN-HUA HSIEH ${ }^{4}$ and CHIH-WEN PENG ${ }^{5}$ \\ ${ }^{1}$ Institute of Medical Sciences, Tzu-Chi University; ${ }^{2}$ Division of Neuro-Oncology, \\ Neuro-Medical Scientific Center, Buddhist Tzu-Chi General Hospital, Hualien; \\ ${ }^{3}$ Center for Neuropsychiatry, China Medical University and Hospital, Taichung; \\ Departments of ${ }^{4}$ Public Health, ${ }^{5}$ Life Science, Tzu-Chi University, Hualien, Taiwan, R.O.C
}

Received June 18, 2009; Accepted August 20, 2009

DOI: 10.3892/ijo_00000454

\begin{abstract}
Interleukin-12 has been elucidated as a powerful anti-cancer factor in pre-clinical research. However, the obstacles of this modality that emerged from human clinical trails included the toxicity of repeated large dose administration and short effective duration. Therefore, a prolonged, constant therapeutic level of interleukin-12 is required to reduce the adverse effects and enhance the therapeutic efficacy. In this study, 54 nude mice were divided into three groups treated with rAAV2 encoding interleukin-12, rAAV2 vector, and PBS, respectively. All nude mice received human glioblastoma multiforme cell line DBTRG implantation. The biochemistry studies included serum levels of interleukin-12, isotypes of immunoglobulin, interferon- $\gamma$, and TNF- $\alpha$. The activated NK cells were sorted from the spleen by flow cytometry and the cytotoxicity of NK cells were evaluated by LDH assay. In the rAAV2 encoding interleukin-12 group, substantial expression of interleukin-12 was obtained with a serum level of $120-150 \mathrm{pg} / \mathrm{ml}$ through the experimental course and a significant increase of activated NK cells was achieved. The splenocytes extracted from the spleen in rAAV2 encoding IL-12 mice strongly exhibited cytotoxic activity compared to the control groups ( $\mathrm{p}<0.001)$. The IgG1, IgG2a, and IgM also showed a significant increase in the rAAV2 encoding IL-12 group compared to the control groups $(\mathrm{p}<0.05)$. The tumor growth rate decreased obviously in the rAAV2 encoding IL-12 group with a significant difference from the control groups $(p<0.001)$. This study demonstrated an encouraging result of immunomodulative therapy in malignant brain tumors by rAAV2 carrying IL-12 through activating NK cells.
\end{abstract}

Correspondence to: Dr Tsung-Lang Chiu, Division of NeuroOncology, Neuro-Medical Scientific Center, Buddhist Tzu-Chi General Hospital, 707, Section 3, Chung-Yang Road, 970 Hualien, Taiwan, R.O.C.

E-mail: poluschiou@gmail.com

Key words: immunotherapy, interleukin-12, adeno-associated virus, glioblastoma multiforme, cytokines, gene therapy

\section{Introduction}

In spite of the traditional treatments of malignant brain tumors, such as surgical excision, radiotherapy, chemotherapy, or the aforementioned concomitant with each other, the prognosis of malignant brain tumor is still unsatisfactory due to the fact that the mean survival time of patients is only 12 months and most patients die within 2 years (1-3). A more effective therapy than the traditional treatments is needed urgently. In the post-genome century, gene therapies have become the mainstream in research on treatment of human diseases, in which cytokine research has been in the majority and has increased from $13 \%$ of all human clinical trials before 2001 to $20 \%$ in 2007. Furthermore, cytokine-mediated therapies also play an important role in the immunomodulative gene therapies of cancer by inducing or enhancing the innate or adaptive immune activity with or without a vector $(4,5)$.

Among the pro-inflammatory cytokines, interleukin-12 (IL-12) is the most powerful one which strongly induces and enhances the innate and adaptive immune responses. IL-12 is composed of a $35 \mathrm{kDa}$ light chain and a $40 \mathrm{kDa}$ heavy chain bound with a di-sulfate chain. Most antigen-presenting cells including macrophage, dendritic cells, and neutrophile are able to secrete IL-12 when encountering pathogens (6). The most remarkable cytotoxic reaction of IL-12 is inducing proliferation and maturation of natural killer cells (NK cells) and cytotoxic $\mathrm{T}$ cells. Moreover, it can also enhance secretion of interferon- $\gamma$ (IFN- $\gamma$ ), tumor necrosis factor- $\alpha$ (TNF- $\alpha)$ and granulocytemacrophage colony-stimulating factor from NK cells or cytotoxic T cells and increase the cytotoxic ability of macrophage and NK cells. In adaptive immunity, IL-12 regulates $\mathrm{T}_{\mathrm{H}} 1 \mathrm{~T}$ cell differentiation and promotes IgG2 production by B cells (7). However, the human clinical trials of recombinant IL-12 protein on malignancy did not show the appreciated consequence as illustrated in the animal study due to its insufficient half-life from protein administration and due to the conflicts between its adverse effects and effective dosages $(8,9)$. The method for re-adopting IL-12 in clinical application should shift the protein administration to genetic regulation or modulation, which has potential to achieve long-persisting therapeutic efficacy and reduce fluctuation of induced immune activity. 
In preclinical anti-cancer investigation, recombinant adenoassociated virus (rAAV) has been demonstrated as an effective vehicle to transduce therapeutic genomes into muscle cells (10). Furthermore, as of June 2008, up to 26 human clinical trials have been submitted to the US FDA using rAAV as the vector for genomic transfer (11). This evidence implies the feasibility of rAAV in human application in the future. The superiority of rAAV in safety and efficiency over other viral vectors has been documented, including the lower pre-existed $32 \%$ serum antibody of AAV compared to $55 \%$ of adenovirus, better transductive affinity of broad cell types compared to only dividing cell of retro-virus, causing no known human disease compared to lung infection of adeno-virus or oncogenicity of retro-virus and stable episomal presentation compared to random integration of retro-virus (12-14). Several human clinical trials have successfully demonstrated the efficacy and safety of rAAV, for example, in 1996, Dong et al successfully treated cystic fibrosis with rAAV mediated cystic fibrosis transmembrane conductance regulator genome transduced into patient lung tissue (15). Kappitt and his colleagues treated advanced Parkinson's disease by implanting rAAV2 encoding GAD gene into the subthalamic nucleus, which improved patient motor function $30 \%$ from Unified Parkinson's Disease Rating Scale (16).

In this study, we investigated the transductive efficiency of rAAV2 encoding IL-12 in vivo, the anti-cancer activity of NK cells/lymphokine-activated cells evoked by IL-12 stimulation in vivo and ex vivo, and the antibody-dependent cell-mediated cytotoxicity of NK cells through isotypes of immunoglobulin produced by B cells. For these purposes, we chose nude mice for this experiment as they lack $\mathrm{T}$ immunity but are present with NK cell and B cell immunity (17-19).

\section{Materials and methods}

Preparation of rAAV2 plasmids. Three plasmids pAAV-MCS, pAAV-RC, and pHelper were purchased from Stratagene. The full length cDNA of IL-12 (InvivoGen) was amplified using polymerase chain reaction and subcloned into pAAVMCS and verified by DNA sequencing (Protec). E. coli (ECOS 101) were prepared as competent cells for plasmids transformation and cultured with 2YT medium (Invitrogen). Three plasmids were extracted from competent cells and quantified with OD260/280, then preserved at $-20^{\circ} \mathrm{C}$ for further utility.

Transfection of 293 cells. HEK 293 cells were cultured in DMEM (Cellgro) with 10\% FBS (Hyclone) and 1\% penicillin/ streptomycin (1\% P/S; Gibco). PBS and $0.05 \%$ trypsin+EDTA (Gibco) were used for cell irrigation and passage. Prior to tranfection of plasmids, cells were calculated and plated for $8 \times 10^{6}$ cells in each dish, then $20 \mu \mathrm{g}$ of each package of plasmids, pAAV-RC, pHelper, and pAAV-IL12 were mixed into $15 \mathrm{ml}$ centrifugal tube which contained $2 \mathrm{ml}, 0.25 \mathrm{M}$ $\mathrm{CaCl}_{2}$. The medium in 293 cell dishes was withdrawn and $20 \mathrm{ml}$ medium (DMEM with $10 \% \mathrm{FBS}$, without $1 \% \mathrm{P} / \mathrm{S}$ ) was added. The plasmid solution was pipetted into a $50 \mathrm{ml}$ centrifugal tube which contained $2 \mathrm{ml} 2$ times HBS and was shook until small powder formation, then poured on the 293 cell dishes for $6 \mathrm{~h}$. The medium was changed with DMEM + $10 \%$ FBS and the culture continued for $65 \mathrm{~h}$.
Table I. The number of mice sacrificed during the experiment and number of retro-bulbal puncture in different groups. ${ }^{a}$

\begin{tabular}{lccc}
\hline Mice grouping & $\begin{array}{c}\text { AAV2/ } \\
\text { IL-12 }\end{array}$ & $\begin{array}{c}\text { AAV2/ } \\
\text { empty }\end{array}$ & PBS \\
\hline No. of mice & 18 & 18 & 18 \\
& & & \\
$\begin{array}{l}\text { No. of sacrificed mice } \\
\left.\quad \text { Muscle staining (6th week }{ }^{b}\right)\end{array}$ & 3 & 3 & 3 \\
$\quad \begin{array}{l}\text { Sorting of activated NK cells } \\
\text { (8th week) }\end{array}$ & 3 & 3 & 3 \\
$\begin{array}{l}\text { No. of puncture } \\
\text { Isotypes of immunoglobulin } \\
\text { (7th week) }\end{array}$ & $4 \times 1$ & $4 \times 1$ & $4 \times 1$ \\
$\quad \begin{array}{l}\text { IL-12 (7, 8, 9, 10th week) } \\
\text { IFN- } \gamma \text { and TNF- } \alpha \text { (8th week) }\end{array}$ & $4 \times 4$ & $4 \times 4$ & $4 \times 4$ \\
\end{tabular}

${ }^{a}$ The mice of AAV2/IL-12 group received 4 punctures for evaluating of IL-12 level at 4 different time points $(4 \times 4), 6$ punctures for isotypes of immunoglobulin at 1 time point $(4 \times 1)$, and 3 punctures for IFN- $\gamma$ and TNF- $\alpha(4 \times 1)$. The choice of mice bled for IL-12 level was in turn, for example, in AAV2/IL-12 treated group, four mice received puncture in the 7 th post-vaccination week then another four mice received puncture at the 8th post-vaccination week and so on. ${ }^{b}$ Post-vaccination week.

Purification of $r A A V 2$. The cultured cells were collected and transferred in equal amounts into four $50 \mathrm{ml}$ tubes for centrifugation at $300 \mathrm{rpm}$ for $10 \mathrm{~min}$. The upper clear liquid was poured out and cell pellets were frozen at $-80^{\circ} \mathrm{C}$ for $20 \mathrm{~min}$. DMEM (30 ml, without FBS and P/S) was added to the cell pellets after re-warming in a $37^{\circ} \mathrm{C}$ water bath for $15 \mathrm{~min}$. The cell pellets were shaken to separate and stored again at $-80^{\circ} \mathrm{C}$ for $20 \mathrm{~min}$. BenZonase ( $20 \mu \mathrm{l}$, Novagen) was added to the tube then re-warmed in a $37^{\circ} \mathrm{C}$ water bath for $30 \mathrm{~min}$. After spinning at $3000 \mathrm{rpm}$ for $15 \mathrm{~min}$, the upper clear liquid was collected and added to $6 \mathrm{ml} \mathrm{10 \%} \mathrm{DOC} \mathrm{(Sigma)} \mathrm{for} \mathrm{reaction}$ for $20 \mathrm{~min}$ at $37^{\circ} \mathrm{C}$. The sample was first filtered through a $5.0 \mu \mathrm{m}$ then a $0.8 \mu \mathrm{m}$ filter. The sample $(120 \mathrm{ml})$ was poured into a prepared heparin column slowly and repeated once. $\mathrm{NaCl} / \mathrm{PBS}$ (0.1 M) was used to irrigate the column then $15 \mathrm{ml}$, $0.4 \mathrm{M} \mathrm{NaCl} / \mathrm{PBS}$ was added. An Amicon Ultra centrifugal tube was prepared, then added to post-filtered $15 \mathrm{ml}, 0.4 \mathrm{M}$ $\mathrm{NaCl} / \mathrm{PBS}$ viral solution. About $1.5 \mathrm{ml}$ viral solution was left after $1800 \mathrm{rpm}$ centrifugation, which was added to $15 \mathrm{ml}$ PBS and spun at $1800 \mathrm{rpm}$ again. Total $1.5 \mathrm{ml}$ solution was left after the last centrifugation, it was pipetted into each of the $1.5 \mathrm{ml}$ Eppendrof micro-centrifuge tubes with a volume of $110 \mu \mathrm{l}$ and stored at $-80^{\circ} \mathrm{C}$ for further utility.

Animal model. The animal use protocol was reviewed and approved by the Institutional Animal Care and Use Committee of Tzu-Chi Hospital. Fifty-four mice were enrolled in this experiment and were divided into three groups which included 18 mice treated with rAAV2 encoding IL-12 cDNA (rAAV2/IL-12) as the experimental group, 18 mice treated with rAAV2 non-coding vector (rAAV2/empty) and 18 mice 


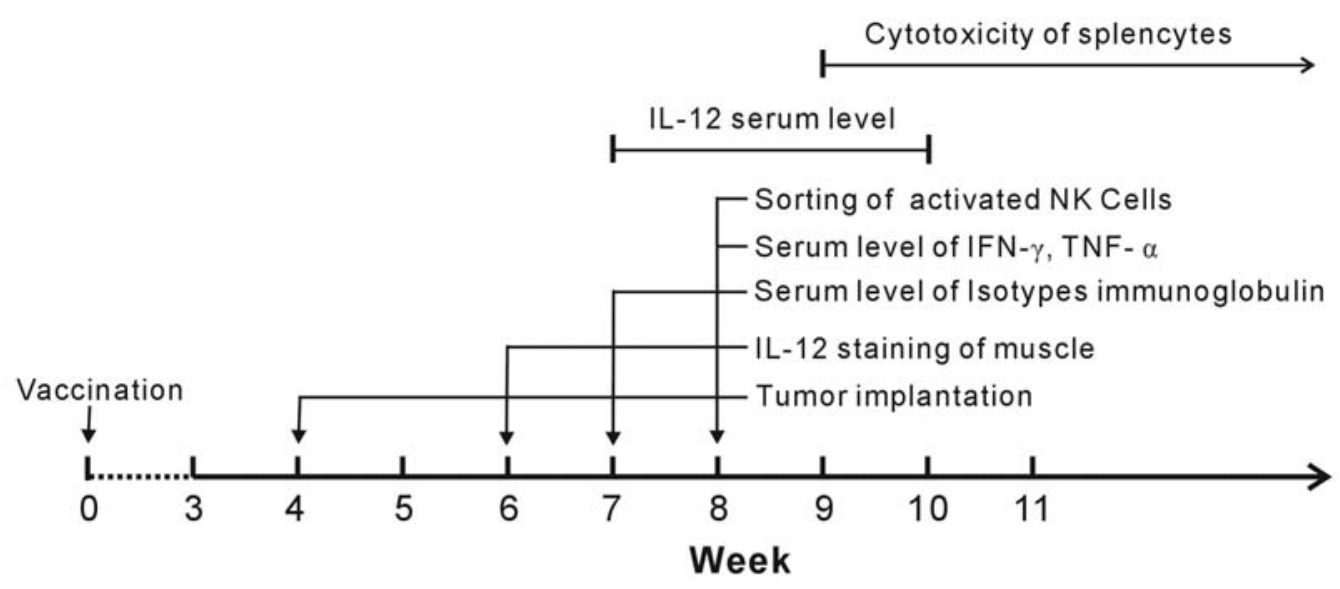

Figure 1. The schema illustrates the time schedule of all the procedures in this animal study.

treated with PBS as the control groups (Table I). All nude mice were purchased from National Laboratory Animal Center R.O.C. and bred in an aseptic room until having a body weight between 20-25 gm. The human glioblastoma multiforme cell line DBTRG was purchased from American Type Culture Collection for xenograft of nude mice. The experimental group received injection on the right thigh with treating reagent of $1 \times 10^{11}$ particles $/ \mathrm{kg} \mathrm{rAAV} / \mathrm{IL}-12$ and the control groups with $1 \times 10^{11}$ particles/kg rAAV2/empty and $60 \mu \mathrm{l}$ PBS solution, individually.

All nude mice received subcutaneous implantation of $5 \times 10^{4}$ DBTRG cells on the flank 4 weeks after vaccination of treating agent. The collection of blood for biochemistry study was harvested by retro-bulbal puncture. The body weight and tumor volume were recorded every 2 days. The biochemical studies performed included serum level of IL-12 being evaluated every week from the 3 rd to the 6th week posttumor implantation (7th to 10th week post-vaccination), isotypes of immunoglobulin being detected in the 3rd week, IFN- $\gamma$ being detected at the 4 th post tumor implantation week, and TNF- $\alpha$ being detected at the 4th post-tumor implantation week as well. Three mice in each of the three groups were sacrificed for sorting activated NK cells in the 4th post-tumor implantation week. Three mice of each of the three groups were sacrificed for IL-12 staining of muscle at the 42 nd day after vaccination. When the tumor volume reached $1000 \mathrm{~mm}^{3}$, the animal was sacrificed and their presumed-survival days were recorded. The organs, including lung, liver, and kidney, were extracted and preserved in $4 \%$ formalin while the spleen was extracted and prepared for LDH cytotoxic assay immediately. In total, 12 rAAV2/IL-12-treated mice, 12 rAAV2/empty-treated mice, and 12 PBS-treated mice completed the course and were estimated for tumor growth and presumed-survival time (Fig. 1 and Table I).

Immunohistochemistry, flowcytometry, ELISA assay and LDH cytotoxic assay. The immunohistochemistry of intracytoplasmic IL-12 staining was performed with a DAB150-150 slide kit which was purchased from Chemicon Internation, Inc. The amount of IL-12, IFN- $\gamma$ and TNF- $\alpha$ were detected with ELISA kits which were purchased from Bender MedSystems, Inc. Isotypes of immunoglobulin were detected with a mouse immunoglobulin isotyping ELISA kit which was purchased from BD Bioscience. The absorbance of immunoglobulin was evaluated with a spectrophotometer (Molecular Devices Emax precision microplate reader). LDH cytotoxic assay was performed with CytoTox 96 Non-Radioactive Cytotoxicity Assay set which was purchased from Promega Corporation. Activated NK cells were sorted by flow cytometry (FACSVantage SE) with R-phycoerythrin-conjugated anti-mouse NK-1.1 (NKR-P1B and NKR-P1C) monoclonal antibody which was purchased from BD Biosciences. All the experimental procedures followed the product information and instructions.

Statistical analysis. The data are reported as mean value \pm standard deviation. The significant difference between the respective groups were compared with one way ANOVA with Bonferroni post test except in the tumor growth experiment, which was analysed with mix effect repeated-measurements ANOVA. The statistical significance of the results was recorded as significant at $\mathrm{p}<0.05$ and as very significant at $\mathrm{p}<0.001$.

\section{Results}

Transduction of muscle cells by rAAV2 encoding $I L-12$. The vaccinated muscle from the right thigh of the posterior limb was excised and stained with a DAB slide kit for IL-12 on frozen section. The muscle cells from the rAAV2/IL-12vaccinated right thigh exhibited brown intracytoplasmic stain of IL-12, which indicated successful transduction of rAAV2 and good expression of IL-12 in muscle cells. There was no brown staining on the non-vaccinated left thigh of the rAAV2/ IL-12-treated, the right thigh of the rAAV2/empty-treated, and the right thigh of the PBS-treated mouse (Fig. 2).

Isotypes of immunoglobulin. The isotypes of immunoglobulin including IgG1, IgG2a, IgG2b, IgG3, IgM, IgA were detected in $4 \mathrm{rAAV} 2 / \mathrm{IL}-12$-treated, $4 \mathrm{rAAV} 2 /$ empty-treated, and 4 PBS-treated mice. The mean absorbance percentage was $56.1 \pm 8.2 \%$ of $\operatorname{IgG} 1,26.9 \pm 7.7 \%$ of $\operatorname{IgG} 2 \mathrm{a}$, and $11.4 \pm 3.1 \%$ of $\mathrm{IgM}$ in the rAAV2/IL-12-treated group; $21.1 \pm 5.0 \%$ of $\mathrm{IgG} 1$, $8.6 \pm 4.0 \%$ of $\operatorname{IgG} 2 \mathrm{a}$ and $2.6 \pm 3.1 \%$ of IgM in the rAAV2/empty- 


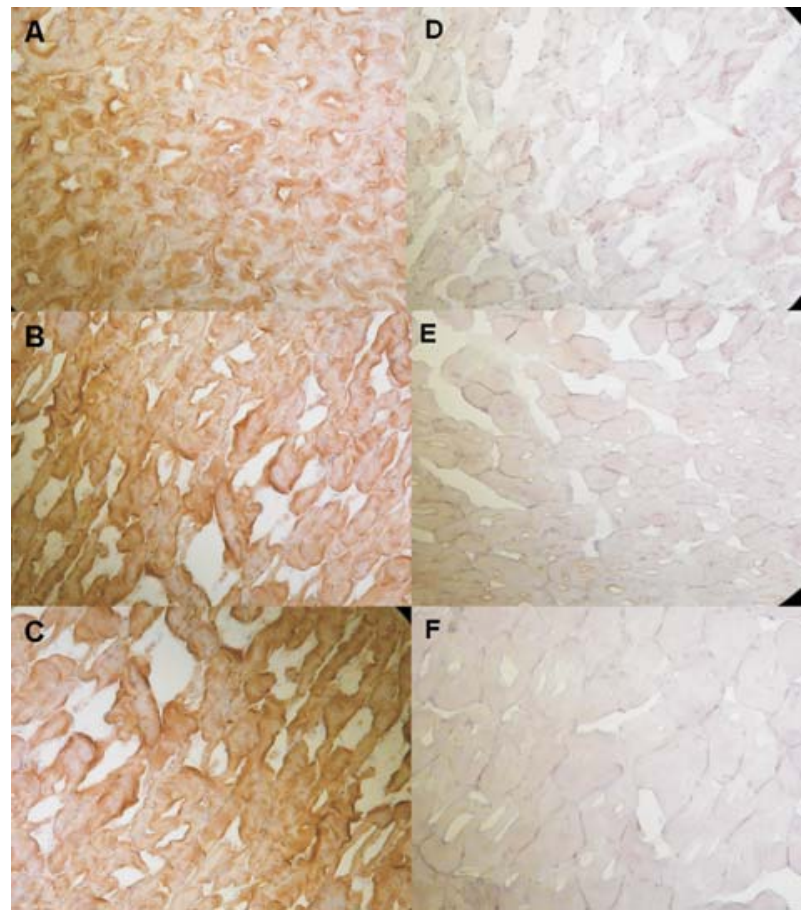

Figure 2. The muscle sections achieved from the thighs of mice and stained with $\mathrm{DAB}$ slide kit at the 6th week after vaccination. The vaccinated right thigh muscle of the rAAV2/IL-12-treated mice illustrated an intracellular brown stain of IL-12 (A-C). There were no visible brown stains on the nonvaccinated left thigh muscle of rAAV2/IL-12-treated mouse (D), vaccinated right thigh muscle of the rAAV/empty-treated mouse (E), and vaccinated right thigh muscle of the PBS-treated mouse (F).

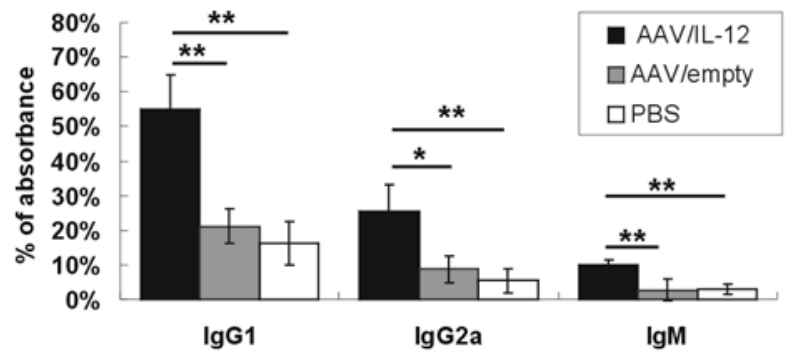

Figure 3. Mean absorbance (\%) of $\operatorname{IgG1}$, IgG2a, and IgM detected on the 3rd post-tumor implantation week (7th week after vaccination) with ELISA assay. In total, 4 AAV2/IL-12-treated (black bar), 4 AAV2/empty-treated (gray bar), and 4 PBS-treated mice (white bar) were estimated and expressed with mean value \pm standard deviation. ${ }^{*}$ Very significant difference $(\mathrm{p}<0.001) ;{ }^{*}$ Significant difference $(\mathrm{p}<0.05)$.

treated group; $21.3 \pm 4.9 \%$ of $\operatorname{IgG} 1,8.7 \pm 4.0 \%$ of $\operatorname{IgG} 2 \mathrm{a}$ and $3.0 \pm 2.7 \%$ of IgM in the PBS-treated group. The ANOVA analysis disclosed significant difference between the rAAV2/IL-12-treated, rAAV2/empty-treated and PBS-treated groups either in the IgG1, IgG2a or IgM absorbance. Significant differences of $\operatorname{IgG} 1, \operatorname{IgG} 2 \mathrm{a}$ and $\operatorname{IgM}$ were observed between the rAAV2/IL-12-treated and the rAAV2/emptytreated groups and also between the rAAV2/IL-12-treated and PBS group. The expression levels of IgG1, IgG2a and IgM were indistinguishable between the rAAV2/empty-treated and the PBS-treated groups (Fig. 3). The absorbance values

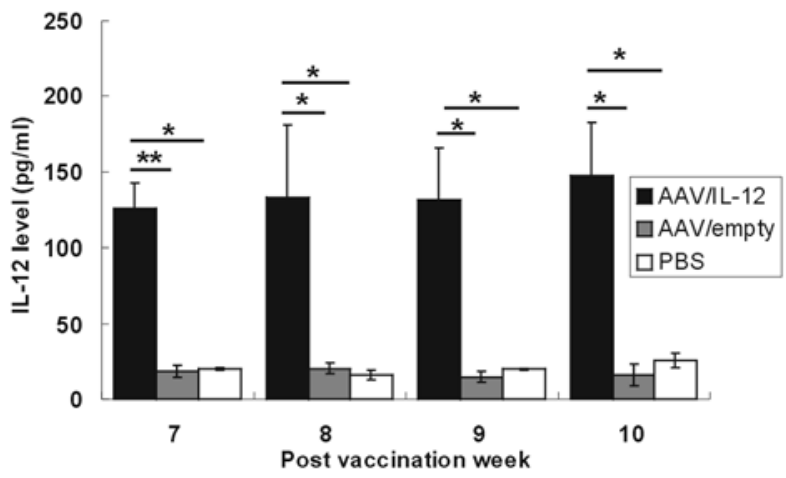

Figure 4. IL-12 serum level $(\mathrm{pg} / \mathrm{ml})$ was detected in the $7,8,9$, and 10th after vaccination by retro-bulbar puncture. Four punctures were done at each different time point in the rAAV/IL-12-treated group (black bar), rAAV2/ empty-treated group (gray bar), and PBS-treated group (white bar). The rAAV/IL-12 displayed a constant level from the 7th to 10th week $\sim 130 \mathrm{pg} / \mathrm{ml}$. ${ }^{* *}$ Very significant difference $(\mathrm{p}<0.001)$; ${ }^{*}$ Significant difference $(\mathrm{p}<0.05)$.

A

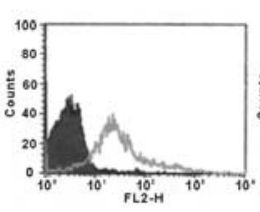

B

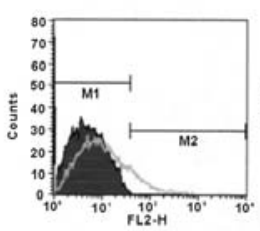

C
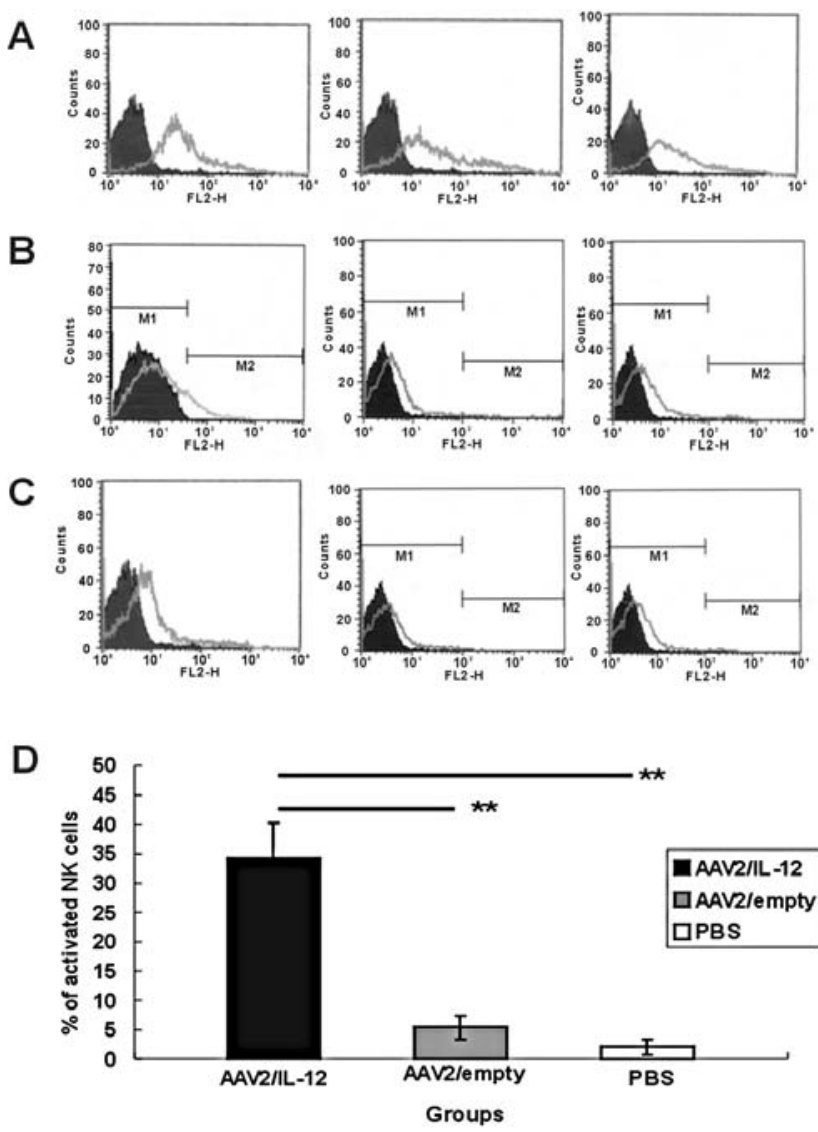

Figure 5. Histograms of flow cytometry of activated NK cells. The activated NK cells were sorted from splenocytes from AAV2/IL-12-treated (A), AAV2/empty-treated (B), and PBS-treated groups (C) in the 8th week after vaccination. The mean $\%$ of activated NK cells sorted from 3 AAV2/IL-12treated mice (black bar), 3 AAV2/empty-treated mice (gray bar), and 3 PBStreated mice (white bar) exhibited obvious increasing in the AAV2/IL-12treated group (D). ${ }^{* *}$ Very significant difference.

were fairly low in the $\operatorname{IgG} 2 \mathrm{~b}, \operatorname{IgG} 3$, and $\operatorname{Ig} A$, which were excluded from this analysis. 


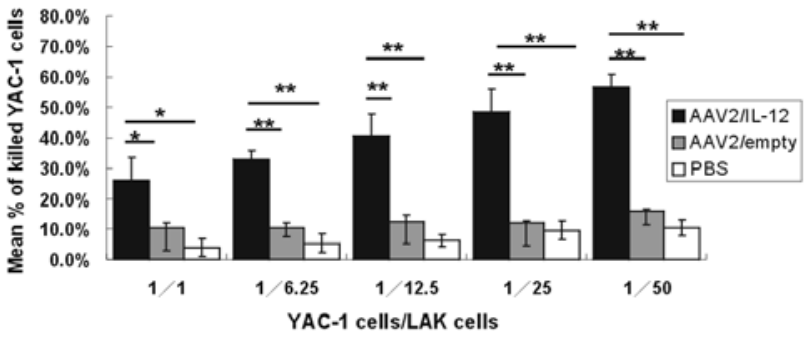

Figure 6. LDH cytotoxic assay of splenocytes on YAC-1 cells. The LDH cytotoxic assay disclosed death percentage of targeted YAC-1 cells killed by splenocytes/LAK cells in different ratios of YAC-1 cells to splenocytes/ LAK cells from 1 to 1,1 to $6.25,1$ to 12,1 to 25 to 1 to 50 (X-axis). In total, 12 rAAV2/IL-12-treated (black bar), 12 AAV/empty-treated (gray bar), and 12 PBS-treated (white bar) mice were estimated for the cytotoxicity of splenocytes/LAK cells. ${ }^{* *}$ Very significant difference $(\mathrm{p}<0.001)$; ${ }^{*}$ Significant difference $(\mathrm{p}<0.05)$.

Serum levels of IL-12 and IFN- $\gamma$. The serum level of IL-12 was quantified with ELISA assay. The mean serum level of IL-12 in the rAAV2/IL-12-treated group was $125.8 \pm 18.3 \mathrm{pg} / \mathrm{ml}$ in the 7 th week post-vaccination, $133.4 \pm 45.0 \mathrm{pg} / \mathrm{ml}$ in the 8 th week, $131.1 \pm 33.0 \mathrm{pg} / \mathrm{ml}$ on the 9 th week, and $147.2 \pm 29.6 \mathrm{pg} / \mathrm{ml}$ in the 10th week. There was very low detectable serum concentration of IL-12 in the control groups. The ANOVA analysis disclosed significant difference between the three groups either in at the $7,8,9$, or 10 th week. Very significant difference was observed in the increased IL-12 level of the rAAV2/IL-12-treated compared to the other 2 groups at all evaluating time points (Fig. 4). The serum level of IFN- $\gamma$ was checked in $3 \mathrm{rAAV} 2 / \mathrm{IL}$-12-treated, $3 \mathrm{rAAV} 2 /$ empty-treated, and 3 PBS-treated mice, which exhibited very low levels, between 5 to $10 \mathrm{pg} / \mathrm{ml}$ (data not shown).

Activating of NK cells. The activated NK cells were sorted by flow cytometry with monoclonal antibody NK 1.1 from the cells extracted from the spleen. The generated histograms showed $34.4 \pm 5.8 \%$ activated NK cells in extracted cells of rAAV2/IL-12-treated group, 5.4 $\pm 1.9 \%$ of rAAV2/emptytreated group, $2.1 \pm 1.3 \%$ of PBS-treated group (Fig. 5). Although the rAAV/empty-treated mice showed a slight increase of the ratio of activated NK cells, the rAAV2/IL-12treated mice exhibited a 6.4 -fold increase in ratio over the rAAV2/empty-treated. These results could be interpreted that abundant functional NK cells could be induced in secondary lymphoid organ, at least in the spleen, by rAAV-mediated IL-12. The ANOVA analysis elicited significant difference between three groups.

Cytotoxicity of splenocytes. Splenocytes/LAK cells obtained from $12 \mathrm{rAAV}$ /IL-12-treated, $12 \mathrm{rAAV}$ /empty-treated, and 12 PBS-treated mice were subjected to LDH cytotoxic assay using YAC-1 (mouse lymphoma cells) as targeted cells. The cytotoxicity of splenocytes/LAK cells from rAAV2/IL-12treated group demonstrated constant increase, from 26.1 \pm 7.5 , $32.9 \pm 2.8,40.6 \pm 7.1,48.5 \pm 7.5$ and $56.5 \pm 4.3 \%$ associated with raising ratio of splenocytes to YAC-1 from 1 to 1 up to 50 to 1 . Splenocytes/LAK cells from the PBS group showed cytotoxic effect $<11 \%$ and rAAV2/empty group showed $10-16 \%$. The ANOVA analysis elicited significant difference between three groups in all of the different ratio groupings. The cytotoxicity

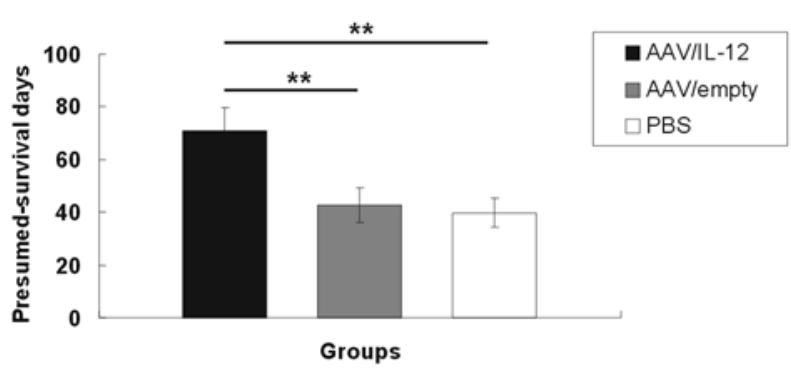

Figure 7. Mean presumed-survival period. The mean presumed-survival period of mice obtained from 12 rAAV2/IL-12-treated (black bar), 12 rAAV2/empty-treated (gray bar), and 12 PBS-treated (white bar) mice. ${ }^{* *}$ Very significant difference $(\mathrm{p}<0.001)$.

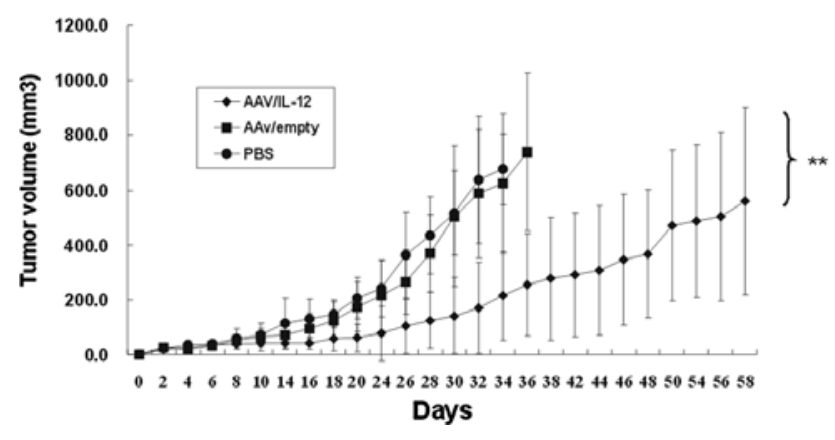

Figure 8. Curves of the mean tumor volume through the course. All the experimental mice were sacrificed for LDH cytotoxic assay when the tumor grew to $1000 \mathrm{~mm}^{3}$, however, the shown data of all groups were terminated at the day of first mouse bearing a tumor reached $1000 \mathrm{~mm}^{3}$, so the tumorgrowth curves showed in the image are from the 2nd to 58th day of the rAAV/IL-12-treated (diamond), 2nd to 36th day of the rAAV/empty-treated (square), and 2nd to 34th day of PBS-treated group (circle). ${ }^{* *}$ Denotes that the inhibition of tumor growth of rAAV/IL-12-treated group was significantly different compared with the other groups.

of the rAAV2/IL-12-treated group was significantly increased compared with the other 2 groups in all of the different ratio groupings. Although the cytotoxic effect of rAAV2/emptytreated was slightly higher than the PBS-treated group, there was no significant difference between them (Fig. 6).

Tumor growth and presumed-survival of animals. The presumed-survival period of an animal was determined when the tumor grew to $\sim 1000 \mathrm{~mm}^{3}$. The mean presumed-survival period was $71.1 \pm 8.5$ days in rAAV2/IL-12-treated, 42.7 \pm 6.8 days in rAAV2/empty-treated, 40.0 \pm 5.3 days, and 40.0 \pm 5.6 days in PBS-treated groups. The ANOVA analysis elicited significant difference between the three groups. The presumedsurvival of AAV2/IL-12 treated group exhibited a significant increase compared with the other groups (Fig. 7). The inoculated-tumor growth was analyzed by mix effect repeatedmeasurements ANOVA that elicited significant inhibition in the AAV2/IL-12-treated group compared to the other 2 groups (Fig. 8).

\section{Discussion}

AAV has been demonstrated as an effective and safe vector in gene conduction for the reasons of currently causing no 
human disease, existing in a living animal for a long period, and having only mild immune response $(12,20)$. For the management of chronic disease in a human subject, rAAV carrying a therapeutic gene has been demonstrated as an effective method for continued expression of mediated genes to correct the genomic deficiency $(15,21)$. In this study, the muscle cells were transduced by rAAV2 and expressed IL-12 constantly through the experimental period. Abundant IL-12 presented in the peripheral blood had the potential to enter secondary lymphoid organs, such as the spleen, to activate NK cells or monocytes and to prime the innate immunity. In addition, IL-12 has been verified with the ability to stimulate B-cells, producing some isotypes of immunoglobulin through the TH2-independent pathway (6). In this study, the IL-12, secreted from the rAAV/IL-12 tranfected muscle cells, induced a nearly 3.4-fold increase of IgG1 and a 4.7-fold of IgG2a over the non-rAAV/ IL-12 transfected cells. Those isotypes of immunoglobulin are known to play an important role in antibody-dependent cell-mediated cytotoxicity of NK cells $(22,23)$.

To ensure that IL-12 could activate NK cells, the splenocytes of each group were sorted for activated NK cells, which showed a tremendous amount of activated NK cells in the rAAV2/IL-12-treated group (Fig. 5). By using the LDH cytotoxic assay, splenocytes/LAK cells were evaluated for their cytotoxicity ex vivo in different ratios to targeted YAC-1 cells, which disclosed rising cytotoxic activity from $26.1 \%$ at the ratio of 1 to 1 up to $56.5 \%$ at the ratio of 50 to 1 . However, the cytotoxic activity was $<24 \%$ in the ratio under 1 to 1 (splenocytes to targeted YAC-1 cells), implying that substantial and prolonged anti-cancer immune activity is crucial for the elimination of inborn stubborn cancer cells.

The pleiotropic IL-12 has been characterized as activating NK cells, cytotoxic T cells and lymphokine-producing monocytes (5). However, since nude mice lack T-cell immunity, the anti-pathogen or anti-cancer activity is derived from NK cells or monocytes only. In this study, tumor-growth was reduced in the rAAV2/IL-12-treated group with the estimated mean survival prolonged 1.6- to 1.8-fold over control groups. It can be expected that in immunocompetent animals or humans with normal $\mathrm{T}$ cell immunity, the prognosis should be improved much more through IL-12-indused $\mathrm{T}_{\mathrm{H}} 1$ cellular immunity.

In spite of the high serum concentration of IL-12, the IFN- $\gamma$ and TNF- $\alpha$ presented quite a low level in the circulatory system in this study. This phenomenon suggested that the interaction of IL-12 with immune cells is carried out predominantly locally, for example the inflammatory tissue or neoplastic tissue, rather than systemically and that the toxic IFN- $\gamma$ was present in circulation for only a short time. This therapeutic modality, muscle cells transfected by rAAV2/IL-12 with a constant serum level of IL-12, provides a safer and more efficient route in preventing morbidity from fluctuation of cytokine concentration such as intermittent administration of recombinant IL-12 $(8,9)$. In addition, from the view of the responses of cytokines and immune cells, the fact that rAAV2 did not induce significant immune activity in this study further improves the safety of rAAV2 applied in mammals.

For the purpose of eradication of cancer cells, a long period of therapy or multiple cycles of treatment are performed routinely by chemotherapy, radiotherapy, or monoclonal antibody targeted therapy in present therapeutic practice. From the preliminary result of clinical trial of hemophilia type $B$ treated with AAV2-mediated factor IX, AAV2 transfected skeletal muscle could express substantial IX up to 10 months after a primary injection (21). In addition, in our experiment, the AAV2-mediated IL-12 expressed by muscle cells of mice persisted at least 10 weeks from initial vaccination. This evidence suggests that the extended therapeutic effect by AAV2-mediated gene transfer could be accomplished by one injection. Consequently, compared with repeated protein administration, the treatment model of AAV2 encoding therapeutic gene will be more efficient and less expensive.

In conclusion, IL-12 can be expressed in muscles transduced by rAAV2 encoding IL-12 and secreted into the circulatory system to maintain a constant serum concentration to further initiate the innate and adaptive immune response. Subsequently, NK cells can be activated and exhibit cytotoxic ability to kill cancer cells in vivo and ex vivo. The final results disclosed a confirmed feasibility of anti-cancer therapy with vaccination of rAAV2 encoding IL-12 through NK-cellrelated cytotoxic immune responses.

\section{References}

1. Daneyemez M, Gezen F, Canakci Z and Kahraman S: Radical surgery and reoperation in supratentorial malignant glial tumors. Minim Invasive Neurosurg 41: 209-213, 1998.

2. Kayama T, Kumabe T, Tominaga T and Yoshimoto T: Prognostic value of complete response after the initial treatment for malignant astrocytoma. Neurol Res 18: 321-324, 1996.

3. Kowalczuk A, Macdonald R, Amidei C, Dohrmann G, Erickson R, Hekmatpanah J, Krauss S, Krishnasamy S, Masters G, Mullan S, Mundt A, Sweeney P, Vokes E, Weir B and Wollman R: Quantitative imaging study of extent of surgical resection and prognosis of malignant astrocytomas. Neurosurgery 41: 10281036, 1997.

4. Dredge K, Marriott J, Todryk S and Dalgleish A: Adjuvants and the promotion of Th1-type cytokines in tumour immunotherapy. Cancer Immunol Immunother 51: 521-531, 2002.

5. Fehniger $T$, Cooper $M$ and Caligiuri $M$ : Interleukin-2 and interleukin-15: immunotherapy for cancer. Cytokine Growth Factor Rev 13: 169-183, 2002.

6. Watford W, Moriguchi M, Morinobu A and O'Shea J: The biology of IL-12: coordinating innate and adaptive immune responses. Cytokine Growth Factor Rev 14: 361-368, 2003.

7. Trinchieri G: Interleukin-12 and the regulation of innate resistance and adaptive immunity. Nat Rev Immunol 3:133-146, 2003.

8. Leonard JP, Sherman ML, Fisher GL, Buchanan LJ, Larsen G, Atkins MB, Sosman JA, Dutcher JP, Vogelzang NJ and Ryan JL: Effects of single-dose interleukin-12 exposure on interleukin12 -associated toxicity and interferon-gamma production. Blood 90: 2541-2548, 1997 .

9. Salem M, Gillanders W, Kadima A, El-Naggar S, Rubinstein M, Demcheva M, Vournakis J and Cole D: Review: novel nonviral delivery approaches for interleukin-12 protein and gene systems: curbing toxicity and enhancing adjuvant activity. $J$ Interferon Cytokine Res 26: 593-608, 2006.

10. Ma H, Lin S, Chiang Y, Li J, Chen S, Tsao Y and Xiao X: Intratumoral gene therapy of malignant brain tumor in a rat model with angiostatin delivered by adeno-associated viral (AAV) vector. Gene Ther 9: 2-11, 2002.

11. Mueller $C$ and Flotte T: Clinical gene therapy using recombinant adeno-associated virus vectors. Gene Ther 15: 858-863, 2008.

12. Chirmule N, Propert K, Magosin S, Qian Y, Qian R and Wilson J: Immune responses to adenovirus and adeno-associated virus in humans. Gene Ther 6: 1574-1583, 1999.

13. Halbert C, Miller A, McNamara S, Emerson J, Gibson R, Ramsey B and Aitken M: Prevalence of neutralizing antibodies against adeno-associated virus (AAV) types 2, 5, and 6 in cystic fibrosis and normal populations: Implications for gene therapy using AAV vectors. Hum Gene Ther 17: 440-447, 2006. 
14. Nakai H, Yant SR, Storm TA, Fuess S, Meuse L and Kay MA: Extrachromosomal recombinant adeno-associated virus vector genomes are primarily responsible for stable liver transduction in vivo. J Virol 75: 6969-6976, 2001.

15. Dong J, Fan P and Frizzell R: Quantitative analysis of the packaging capacity of recombinant adeno-associated virus. Hum Gene Ther 7: 2101-2112, 1996

16. Emborg M, Carbon M, Holden J, During M, Ma Y, Tang C, Moirano J, Fitzsimons H, Roitberg B, Tuccar E, Roberts A Kaplitt $\mathrm{M}$ and Eidelberg D: Subthalamic glutamic acid decarboxylase gene therapy: changes in motor function and cortical metabolism. J Cereb Blood Flow Metab 27: 501-509, 2007.

17. Chmielarczyk W, Engler H, Ernst R, Opitz U and Kirchner H: Injection of anti-thy-1.2 serum breaks genetic resistance of mice against herpes simplex virus. J Gen Virol 66: 1087-1094, 1985

18. Karupiah G, Blanden R and Ramshaw I: Interferon gamma is involved in the recovery of athymic nude mice from recombinant vaccinia virus/interleukin 2 infection. J Exp Med 172: 1495-1503, 1990.

19. Hioki K, Maruo K, Suzuki S, Kato H, Shimamura K, Saito M and Nomura T: Studies on beige-nude mice with low natural killer cell activity 1 . Introduction of the bg gene into nude mice and the characteristics of beige-nude mice. Lab Anim 21: 72-77, 1987.
20. Kay MA and Nakai $\mathrm{H}$ : Looking into the safety of AAV vectors. Nature 424: 251-251, 2003.

21. Manno CS, Chew AJ, Hutchison S, Larson PJ, Herzog RW, Arruda VR, Tai SJ, Ragni MV, Thompson A, Ozelo M, Couto LB, Leonard DGB, Johnson FA, McClelland A, Scallan C, Skarsgard E, Flake AW, Kay MA, High KA and Glader B: AAV-mediated factor IX gene transfer to skeletal muscle in patients with severe hemophilia B. Blood 101: 2963-2972, 2003.

22. Fukui H, Overton W, Herberman R and Reynolds C: Natural killer cell activity in the rat. VI. Characterization of rat large granular lymphocytes as effector cells in natural killer and antibody-dependent cellular cytotoxic activities. J Leukoc Biol 41: 130-142, 1987.

23. Terme M, Ullrich E, Delahaye N, Chaput N and Zitvogel L: Natural killer cell-directed therapies: moving from unexpected results to successful strategies. Nat Immunol 9: 486-494, 2008. 